\title{
Silencing STAT3 with short hairpin RNA enhances radiosensitivity of human laryngeal squamous cell carcinoma xenografts in vivo
}

\author{
XIAOMING LI ${ }^{1}$, HAIRU WANG ${ }^{1,2}$, XIUYING LU ${ }^{1}$ and BIN DI ${ }^{1}$ \\ ${ }^{1}$ Department of Otolaryngology-Head and Neck Surgery, Bethune International Peace Hospital, \\ Shijiazhuang, Hebei 050082; ${ }^{2}$ The Pepole's Hospital of Haikou, Haikou, Hainan 570208, P.R. China
}

Received August 6, 2010; Accepted September 20, 2010

DOI: $10.3892 / \mathrm{etm} .2010 .156$

\begin{abstract}
Short hairpin RNA (shRNA) targeting signal transducer and activator of transcription 3 (STAT3) potentiate the radiosensitivity of human laryngeal squamous carcinoma cells in vitro. In the present study, we investigated the inhibitory effect of STAT3 shRNA plus radiotherapy on nude mouse laryngeal squamous cell carcinoma xenografts. The xenotransplanted tumors were treated with STAT3 shRNA, with or without radiation, following a planned scheme. The inhibition rate for tumor growth was calculated and the tumor growth curve was plotted. In addition, the expression of p-STAT3, B cell lymphoma 2 (Bcl-2), p53, vascular endothelial growth factor (VEGF) protein and intratumoral microvessel density (MVD) was determined by immunohistochemistry. Flow cytometry was used to detect the rate of cell apoptosis. The results revealed that STAT3 shRNA transfection plus radiotherapy significantly minimized tumor volume and increased the rate of tumor inhibition. p-STAT3 protein expression and intratumoral MVD were observed to be down-regulated, whereas apoptosis was increased. There was a positive correlation between the expression of p-STAT3 and $\mathrm{Bcl}-2$, and also between the expression of p53 and VEGF, and MVD. These findings indicate that STAT3 shRNA potentiate the radiosensitivity of laryngeal carcinoma xenografts in vivo by regulating downstream signaling proteins in the STAT3 pathway.
\end{abstract}

\section{Introduction}

Radiotherapy is a crucial treatment method in the management of human laryngeal carcinoma. Unfortunately, in some cases, little tumor-controlling efficacy is achieved by radiation

Correspondence to: Professor Xiaoming Li, Department of Otolaryngology-Head and Neck Surgery, Bethune International Peace Hospital, 398 Zhongshan West Road, Shijiazhuang, Hebei 050082, P.R. China

E-mail: xmlmo@126.com

Key words: signal transducer and activator of transcription 3, RNA interference, laryngeal neoplasms, xenograft tumor, radiosensitivity alone $(1,2)$, due to the inherent radioresistance of this tumor. The development of new strategies to improve the sensitivity to radiotherapy of cancer is absolutely necessary. For this purpose, in recent years, potential targets for therapeutic intervention of therapy-resistant cancers have been extensively studied. Among the various related factors investigated, signal transducer and activator of transcription 3 (STAT3) is an important potential therapeutic target.

Physiologically, STAT3 has diverse biological functions, including the modulation of cell growth and cell differentiation, and the regulation of apoptosis (3-5). Moreover, STAT3 has been shown to be constitutively activated in various types of human cancer and to be necessary for tumor cell growth (6). In human cancer, STAT3 participates in oncogenesis through the modulation of p53 expression (7), the regulation of cell cycle control genes, including C-Myc (8-10) and cyclinD1/D2 (11), the up-regulation of genes encoding apoptosis inhibitors, such as $\mathrm{B}$ cell lymphoma 2 (Bcl-2), Bcl-xL, survivin and $\mathrm{Mcl}-1$ $(5,12-15)$, and the induction of angiogenesis by vascular endothelial growth factor (VEGF) $(13,16)$.

Radiosensitivity is affected by changes in the cell cycle, programmed cell death, DNA injury repair, and other mechanisms regulated by oncogenes after radiation. In view of the fact that many factors related to the tumor cell cycle, apoptosis and DNA injury repair are downstream of the STAT3 pathway, we hypothesized that STAT3 may be involved in cancer radioresistance.

In our previous study (17), we successfully demonstrated that the apoptosis of hep-2 cells is significantly increased by blocking the STAT3 pathway with short hairpin RNA (shRNA) combined with radiation in vitro, indicating the potential radiosensitization effects of STAT3 shRNA-based RNA interference (RNAi). This is a new technique that inhibits mRNA expression by inducing the sequence-specific destruction of homologous mRNA in cells with small interference RNA (siRNA). Here, to confirm our previous findings, a xenograft model of human laryngeal squamous cell carcinoma was established in nude mice, and a constructed recombinant plasmid vector carrying human STAT3 shRNA was transfected into the tumor-bearing mice followed by radiation, with the aim of examining its efficacy in the inhibition of tumor growth. The results demonstrate that shRNA targeting STAT3 potentiate the radiosensitivity of human laryngeal carcinoma xenografts in vivo. 


\section{Materials and methods}

Reagents. RPMI-1640 media, Opti-MEMI and Lipofectamine 2000 were purchased from Invitrogen Corp. (Carlsbad, CA, USA). Plasmid pGPU6/GFP/Neo and siRNA oligonucleotides were provided by Gene Pharma Corporation (Shanghai, China). The target region of STAT3 siRNA was selected and recombinant plasmids were constructed according to our previous study (17). The Wizard ${ }^{\circledR}$ Plus Megapreps DNA Purification System was purchased from Promega (USA). The AMV First Strand cDNA Synthesis kit and primers were products of Sangon Biological Engineering Technology and Services Corp. (Shanghai, China). STAT3, p-STAT3 and Bcl-2 mouse monoclonal antibodies were from Santa Cruz Biotechnology (Santa Cruz, CA, USA). Rabbit anti-human p53 polyclonal antibody was obtained from Seitz Biological Technology Co., Ltd. (Beijing, China) and Rabbit anti-human VEGF polyclonal antibody was from Boster Biological Technology, Ltd. (Wuhan, China). CD34 mouse monoclonal antibody, the SP kit and DAB developer were from Zhongshan Goldenbridge Bio-technology Co., Ltd. (Beijing, China). Propidium iodide was purchased from Sigma (USA).

Tumor transfection and treatment. Male BALB/c nude mice, aged 4-5 weeks and weighing 12-18 g, were obtained from the Medical Department of Peking University Laboratory Animal Center (Beijing, China) and housed under specific pathogenfree conditions at the Bethune International Peace Hospital (Shijiazhuang, China) in accordance with the National Regulations on Animal Experiments and Animal Welfare. To generate the tumor xenografts, $2 \times 10^{6}$ viable hep- 2 cells were subcutaneously injected into the right-side back of the mice. When tumors reached a volume of $\sim 150 \mathrm{~mm}^{3}$ (on day 14), 28 tumor-bearing mice were randomly divided into four groups: the negative control group (pshNeg), tumors injected with negative plasmid; the STAT3 siRNA group (pshSTAT3), tumors treated with STAT3 shRNA recombinant plasmid alone, without irradiation; the irradiation group (IR), tumors exposed to radiation alone, with $5 \mathrm{~Gy}$ of $\gamma$-rays per irradiation; the combination group (pshSTAT3 plus IR), tumors treated with STAT3 shRNA recombinant plasmid combined with irradiation as above.

To perform the in vivo gene transfection, the mice in the pshNeg, pshSTAT3, and pshSTAT3 plus IR groups were intratumorally injected with a $200 \mu \mathrm{l}$ mixture of plasmid $(20 \mu \mathrm{g} / 20 \mu \mathrm{l}$ plasmid $+50 \mu 1$ Lipofectamine $+130 \mu 1$ serum-free RPMI-1640 culture medium). The mice in the IR group were injected with the same amount of control mixture (50 $\mu 1$ Lipofectamine + $150 \mu 1$ serum-free RPMI-1640 culture medium). Intratumoral injection was performed on days $0,3,6,9,12,15,18$ and 21 , with day 0 representing the first day of injection. To test the transfection efficiency, fresh tumor cells were obtained at $48 \mathrm{~h}$ post-transfection from a separate group of animals in a parallel single transfection experiment, and the transfection efficiency was measured by flow cytometry (FCM). On days 2, 5, 8 and 11 of the planned treatment scheme, radiotherapy was performed with $\gamma$-rays on the tumors only using a ${ }^{60} \mathrm{Co}$ unit, with the animals immobilized and biologically isolated from ambient air using a special device. The remaining parts of the animals were protected by a $1-\mathrm{cm}$ thick stereotype. Projectile's Ueno
Area was $4 \times 4 \mathrm{~cm}$, with a source tumor distance of $100 \mathrm{~cm}$ and an absorbed dose rate of $78.79 \mathrm{cGy} / \mathrm{min}$. Tumor volumes were estimated four times weekly according to the formula $\mathrm{v}=\mathrm{a}^{2} \mathrm{~b} / 2$, where $\mathrm{a}$ and $\mathrm{b}$ are the shortest and longest diameter, respectively (18). Upon termination of the experiment, the mice were sacrificed by cervical dislocation, and the tumors were excised for weighing, immunohistochemistry and FCM. Tumor growth inhibition rates were calculated using the formula (1 - average tumor weight of experimental group/average tumor weight of control group) x $100 \%$.

Semi-quantitative RT-PCR analysis. The cell suspension was prepared from fresh tumor tissues. Total RNA was extracted from $1 \times 10^{6}$ fresh tumor cells using TRIzol reagent according to the manufacturer's instructions. RT-PCR was performed using the two-step method. cDNA was synthesized according to the protocol of the AMV First Strand cDNA Synthesis kit. STAT3 gene primers were: forward, 5'-gtcagatgccaaatgc-3'; reverse, 5 '-cctggaggcttagtgc-3'. $\beta$-actin primers were: forward, 5'-GCATGGGTGCCCCGACGTTG-3'; reverse, 5'-GCTCCG GCCAGAGGCCTCAA-3'. The PCR reaction was performed using a PCR instrument (UNOII, Biometra, Germany). The reaction conditions were: $95^{\circ} \mathrm{C}$ for $5 \mathrm{~min}$, followed by 30 cycles at $95^{\circ} \mathrm{C}$ for $30 \mathrm{sec}, 55^{\circ} \mathrm{C}$ for $45 \mathrm{sec}, 72^{\circ} \mathrm{C}$ for $60 \mathrm{sec}$, and a final elongation at $72^{\circ} \mathrm{C}$ for $10 \mathrm{~min}$. PCR products were separated on a $2 \%$ agarose gel, and visualized by ethidium bromide staining.

Gene expression analysis and intratumoral microvessel density $(M V D)$. Tumor tissues were fixed in $4 \%$ paraformaldehyde and embedded in paraffin, then 4-mm sections were cut and prepared. Immunohistochemical stainning was performed according to the standard protocol of the SP kit. In brief, after dewaxing and rehydration, the sections were subjected to heatinduced antigen retrieval in a high pressure cooker, quenched in reagent $\mathrm{A}\left(3 \% \mathrm{H}_{2} \mathrm{O}_{2}\right.$ methanol) for 10 min to remove endogenous peroxidase activity, washed in PBS, and then incubated with normal goat serum for $30 \mathrm{~min}$ to block non-specific binding sites. Subsequently, the sections were incubated with primary antibodies (STAT3, p-STAT3, Bcl-2, p53, VEGF and CD34) overnight at $4^{\circ} \mathrm{C}$. After the primary antibody was removed, the slides were washed with PBS and incubated with reagent $\mathrm{C}$ (biotin-conjugated goat-anti-mouse $\mathrm{IgG}$ ) for $30 \mathrm{~min}$. Sections were rinsed with PBS and developed with reagent $\mathrm{D}$ (horseradish-peroxidase-labeled pronase avidin) for $15 \mathrm{~min}$, then counterstained for 3-5 min with hematoxylin and coloured by 3,3'-diaminobenzidine (DAB). Sections from human laryngeal carcinoma known to have abundant STAT3, p-STAT3 and related protein (Bcl-2, p53 and VEGF) expression served as the positive control. For the negative controls, PBS was used rather than the primary antibodies. Protein staining was quantified using computer-assisted image analysis with Image Pro Plus software (Media Cybernetics) (19). MVD was assessed by the hot spot method (20).

Analysis of apoptosis by flow cytometry. Single cell suspensions were prepared from fresh tumor tissues. Cell viability was assessed by typan blue exclusion, and the samples were fixed in $70 \%$ ethanol at $4^{\circ} \mathrm{C}$ for $24 \mathrm{~h}$. Cells were resuspended in PBS and stained with propidium iodide $(50 \mathrm{mg} / \mathrm{l})$ according to the manufacturer's instructions, then analyzed by FCM 


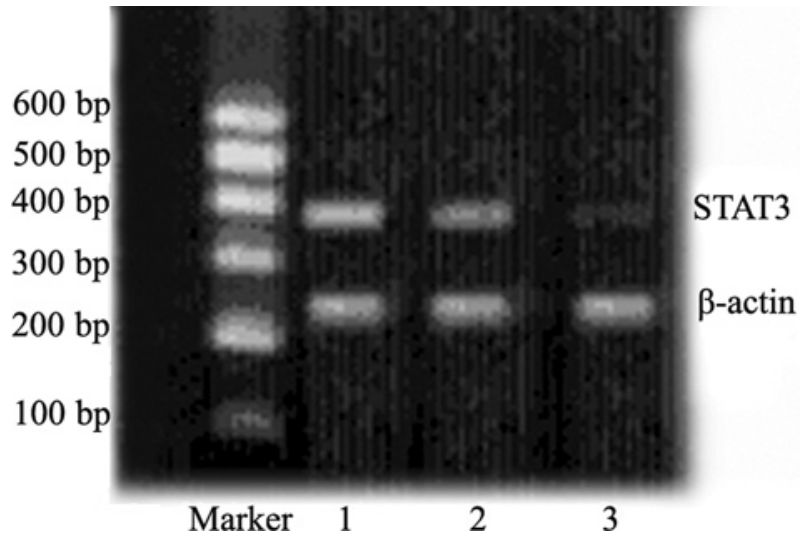

Figure 1. Semi-quantitative RT-PCR analysis of STAT3 mRNA in xenograft tumors. Nude tumor-bearing mice were transfected with negative plasmid (pshNeg) or plasmid for the expression of STAT3 siRNA (pshSTAT3). RT-PCR was performed at $48 \mathrm{~h}$ post-transfection. The expression of STAT3 mRNA in the pshSTAT3 xenograft tumors was significantly down-regulated Transfection with negative plasmid had no effect on the expression of STAT3 mRNA. Lane 1, blank control group; 2, negative control group; 3, shRNA recombinant plasmid group.
(Epics-XLII; Beckman Coulter, USA). For DNA staining, a total of 10,000 cells were counted and analyzed by Muticycle AV software. The stained cells were analyzed by FCM. Forward light scatter characteristics were used to exclude cell debris from the analysis. Apoptotic cells were determined by their hypochromic subdiploid staining profiles.

Statistical analysis. Data were expressed as the mean \pm standard deviation (SD). Statistical analyses were performed using SPSS15.0 software. One-way ANOVA was used to determine statistical differences between the experimental groups. After normalization, two-sided variance were analyzed by Pearson's correlation coefficient. $\mathrm{P}<0.05$ was considered statistically significant.

\section{Results}

Effects of STAT3 shRNA on mRNA expression in vivo. As shown in Fig. 1, the expression of STAT3 mRNA was significantly down-regulated $48 \mathrm{~h}$ after transfection in tumor cells
A

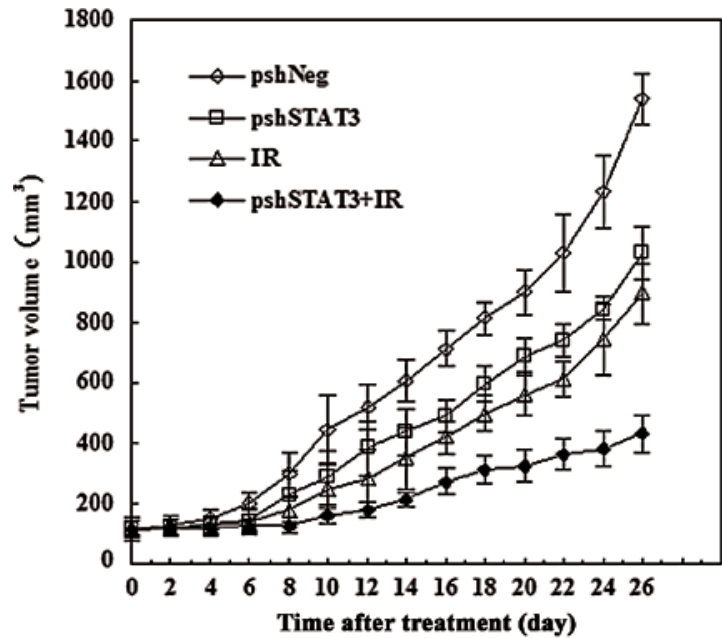

C

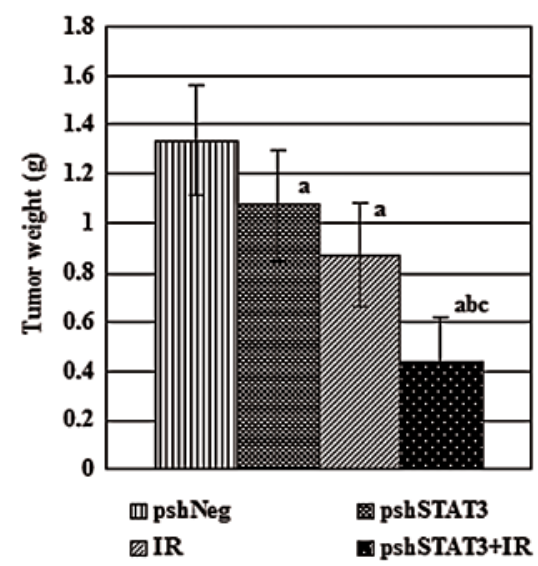

B

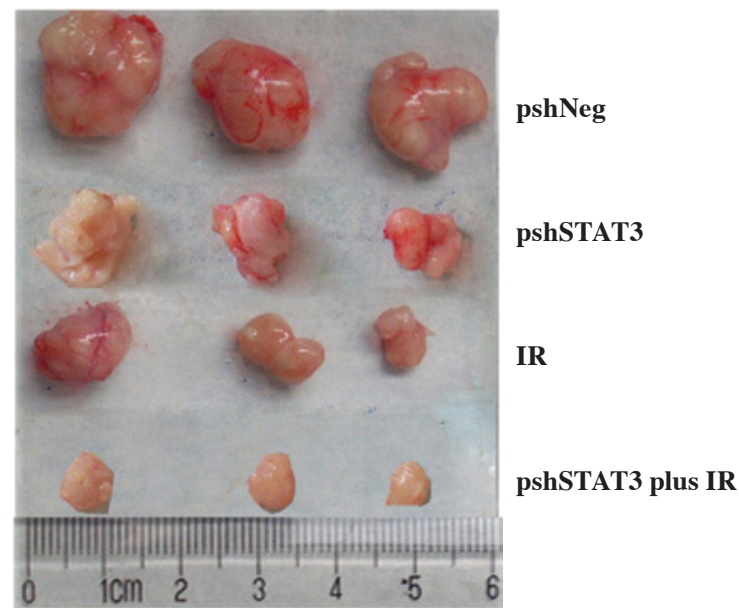

D

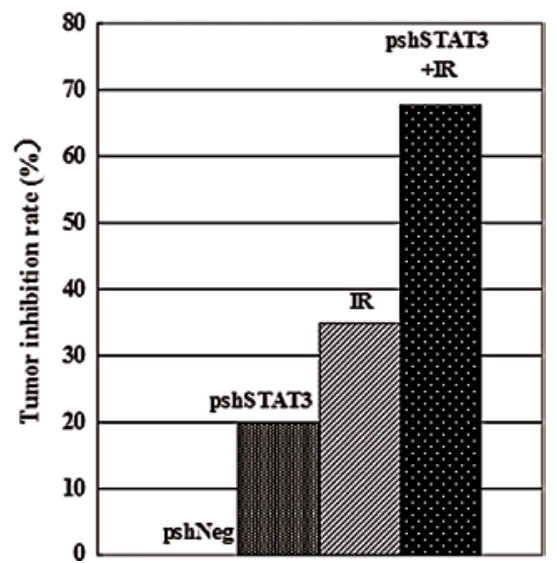

Figure 2. Effect of combined treatment with pshSTAT3 plus radiation on xenograft tumor growth in vivo. pshNeg, tumors injected with negative plasmid; pshSTAT3, tumors treated with STAT3 shRNA recombinant plasmid alone; IR, tumors exposed to radiation alone; pshSTAT3 plus IR, tumors treated with STAT3 shRNA recombinant plasmid in combination with irradiation. (A) Tumor volume. From the initiation of treatment, tumors were measured four times weekly with calipers. Tumor volumes were calculated and data were plotted using the geometric mean for each group vs. time. Each point represents the mean tumor volume $( \pm \mathrm{SD})$ of measurements from the 7 mice in each treatment group. (B) Representative tumors from each group. The pshSTAT3 plus IR group had the smallest volume among the four groups. (C) Tumor weight. Differences in tumor weight among the groups was statistically significant, with the lightest being in the pshSTAT3 plus IR group. ${ }^{a} \mathrm{P}<0.05$ vs. pshNeg; ${ }^{\circ} \mathrm{P}<0.05$ vs. IR; ${ }^{\mathrm{c}} \mathrm{P}<0.05$ vs. pshSTAT3. (D) Tumor growth inhibition. Inhibition rates in the pshSTAT3, IR and pshSTAT3 plus IR groups were $19.68,34.76$ and $67.70 \%$, respectively. 

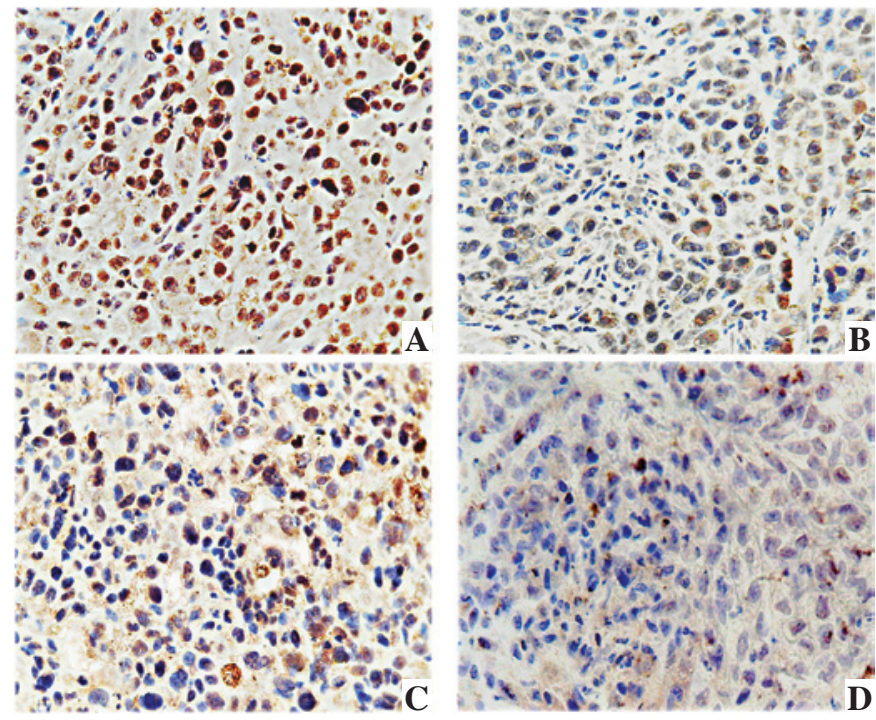

\section{E}

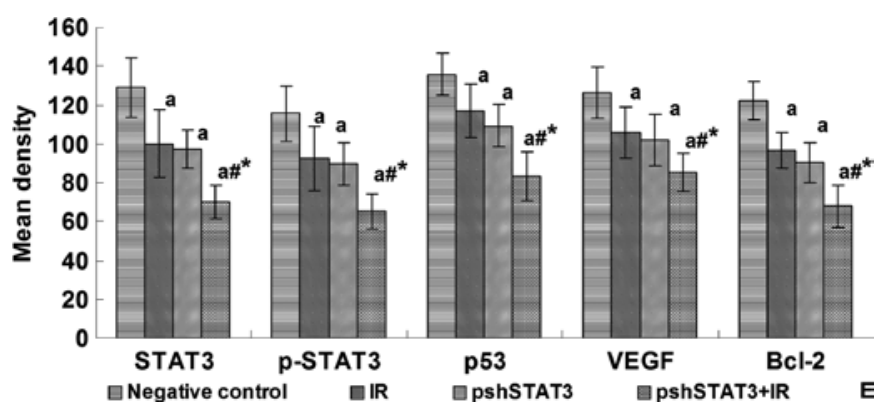

Figure 3. Effects of pshSTAT3 on p-STAT3 expression in vivo. The expression of p-STAT3 protein in the xenografts was evaluated by immunohistochemistry. Image analysis was carried out in four randomly selected fields per section, from seven consecutive sections per group (magnification, x400). (A) pshNeg; (B) pshSTAT3; (C) IR; (D) pshSTAT3 plus IR. (E) Computerized image analysis of the expression levels of the related proteins, including STAT3, p-STAT3, p53, Bcl-2 and VEGF, showing notable features of protein expression. STAT3, p-STAT3, p53, Bcl-2 and VEGF protein expression were significantly reduced in the pshSAT3 plus IR group ( ${ }^{\mathrm{a}} \mathrm{P}<0.05$ vs. negative control group; ${ }^{\mathrm{P}} \mathrm{P}<0.05$ vs. irradiation group; ${ }^{*} \mathrm{P}<0.05$ vs. pshSTAT3 group, $\mathrm{n}=7$ ).

from animals transfected with plasmid carrying STAT3 shRNA as compared to the negative controls. This confirmed the transfection efficiency of the experimental scheme applied for the in vivo transfection.

Suppression of xenograft tumor growth. After confirming the in vivo transfection efficiency, we analyzed the therapeutic potential of pshSTAT3 plus irradiation. Upon termination of the experiment, tumor volumes (mean $\pm \mathrm{SD}$ ) were $1536.83 \pm 83.27$, $1030.67 \pm 89.03,894.67 \pm 99.19$ and $433.83 \pm 60.89 \mathrm{~mm}^{3}$ for the pshNeg, pshSTAT3, IR, and pshSTAT3 plus IR groups, respectively (Fig. 2A). Differences between the groups were statistically significant $(\mathrm{F}=174.07, \mathrm{P}=0.000)$. The outcomes of various treatments on tumor volume and appearance are shown in Fig. 2B. There was a significant difference in tumor weight among the different groups $(\mathrm{F}=23.10, \mathrm{P}=0.000)$, with the pshSTAT3 plus IR group having the lightest tumor weight (Fig. 2C). The strongest tumor growth inhibitory effect was observed in the pshSTAT3 plus IR group, which had a tumor inhibition rate of $67.7 \%$ (Fig. 2D).
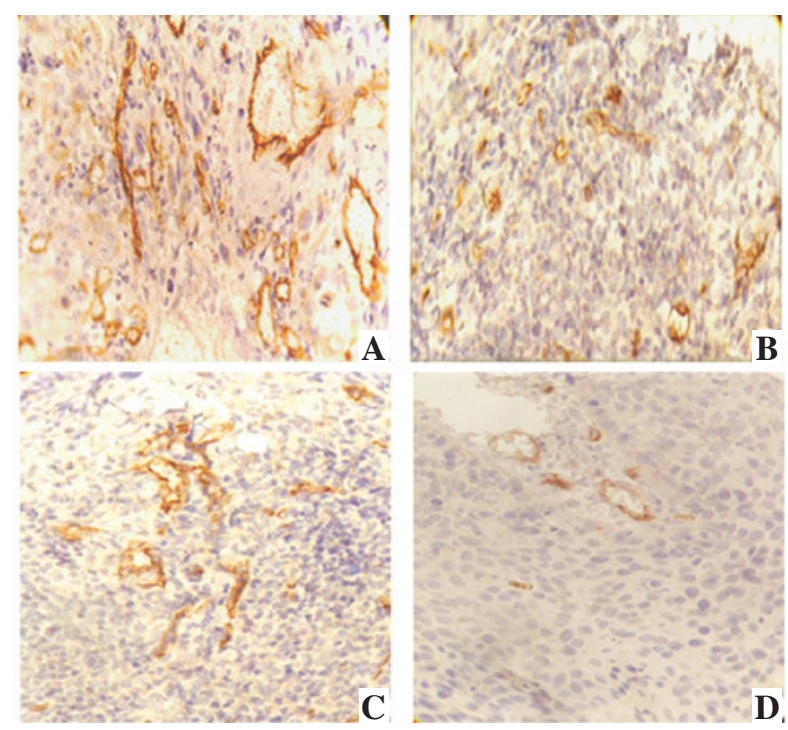

$\mathbf{E}$

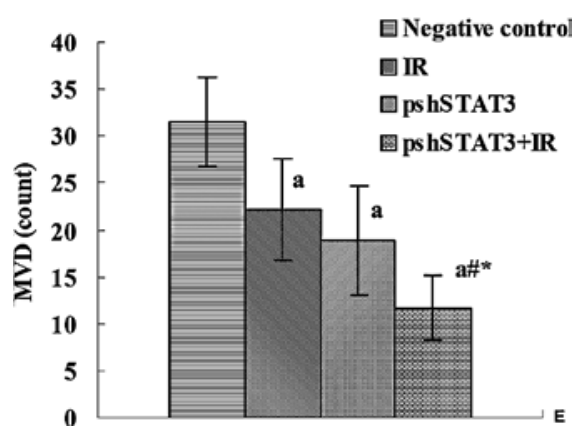

Figure 4. Immunohistochemical staining of CD34 for the evaluation of angiogenesis. The most vascularized areas of the tumors were identified in a low-power field (x100), and vessels were counted in five high-power fields (x200). The average of vessels with CD34 staining in four hot regions was calculated to determine the microvessel density (MVD) counts. (A) Tumor section from the pshNeg group showing highly vascularized tumor tissue. (B and C) Tumor sections from the pshSAT3 and IR groups showing moderately stained vascularized endothelial cells. (D) Similar section from the control group showing only a few positively-stained vascular endothelial cells. Magnification, x200. (E) MVD was quantified in tumor sections from the four groups. There was a significant difference among the groups $(\mathrm{F}=19.196$, $\mathrm{P}<0.05)$. MVD in negative control group was $31.43 \pm 4.76$, compared to $11.67 \pm 3.41$ in the pshSTAT3 plus IR group $(\mathrm{P}<0.05)$. Bars, $\mathrm{SD} .{ }^{\mathrm{a}} \mathrm{P}<0.05$ vs negative control group; ${ }^{\#} \mathrm{P}<0.05$ vs. irradiation group; ${ }^{*} \mathrm{P}<0.05$ vs. pshSTAT3 group, $\mathrm{n}=7$.

Protein expression of STAT3, $p$-STAT3, p53, VEGF and Bcl-2. Immunostaining for STAT3 and VEGF was mainly detectable in the cytoplasmic membrane and cytoplasm. Positive expression of p-STAT3, p53 and Bcl-2 proteins was mainly found in the nuclei of the tumor cells. Strong staining for STAT3, p53, Bcl-2 and VEGF was observed in the negative control group. Most tumor cells had weak or undetectable staining for the above proteins in the pshSTAT3 plus IR group (Fig. 3A-D). Computerized image analysis revealed that the mean density of p-STAT3 decreased in a stepwise pattern in the pshNeg (115.6 \pm 14.2$)$, IR $(92.7 \pm 16.4)$, pshSTAT3 (89.7 \pm 1.0$)$ and pshSTAT3 plus IR $(65.2 \pm 8.9)$ groups $(\mathrm{F}=17.779, \mathrm{P}<0.05)$. For each individual protein, including p53, Bcl-2 and VEGF, the level of protein expression among the different groups was statistically different $(\mathrm{F}=22.969,34.285$ and 13.306 , all $\mathrm{P}<0.05)$. Compared to the other three groups, $\mathrm{p} 53, \mathrm{Bcl}-2$ and 


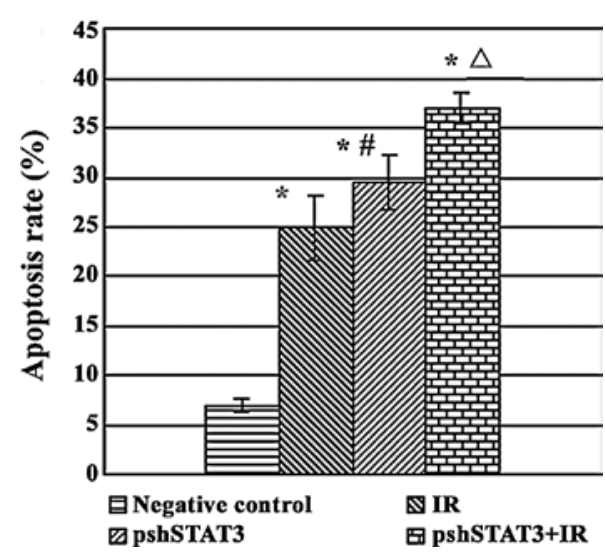

Figure 5. Results of tumor cell apoptosis in different groups (mean \pm SD) The highest apoptosis rate was in the pshSTAT3 plus IR group $(37.04 \pm 1.59 \%)$ and the lowest in the negative control group $(6.89 \pm 0.67 \%)$. Radiation and pshSTAT3 resulted in moderate apoptotic changes with an apoptosis rate of $24.87 \pm 3.26$ and $29.49 \pm 2.69 \%$, respectively. Data were analyzed by one-way ANOVA $(\mathrm{F}=122.40, \mathrm{P}<0.05)$ and the post hoc $\mathrm{SNK}$ test $\left({ }^{*} \mathrm{P}<0.05\right.$ vs. negative control group; ${ }^{\wedge} \mathrm{P}<0.05$ vs. IR or pshSTAT3 group; ${ }^{\#} \mathrm{P}>0.05$ vs. IR group).

Table I. Analysis of correlation between factors.

\begin{tabular}{lcc}
\hline & $\mathrm{r}^{*}$ & P-value \\
\hline p-STAT3 vs. p53 & 0.738 & $0.000<0.01$ \\
p-STAT3 vs. Bcl-2 & 0.727 & $0.000<0.01$ \\
p-STAT3 vs. VEGF & 0.735 & $0.000<0.01$ \\
p53 vs. MVD & 0.784 & $0.000<0.01$ \\
VEGF vs. MVD & 0.641 & $0.000<0.01$ \\
Bcl-2 vs. AP & -0.883 & $0.000<0.01$ \\
\hline
\end{tabular}

*Pearson correlation coefficient.

VEGF protein expression was significantly reduced in the pshSAT3 plus IR group ( $\mathrm{P}=0.000,0.000$ and 0.018) (Fig. 3E).

CD34 expression and MVD counting. Expression of CD34 in the pshSTAT3 plus IR group was weak or even negative, whereas it was strong in the negative control group. The newborn vascular endothelial cells were stained brown or yellow. Irregular lumens and immature vessels were often present (Fig. 4A-D). Results from MVD counting revealed that the MVD values varied widely and showed significant difference among the four groups $(\mathrm{F}=19.196, \mathrm{P}<0.05)$. MVD values were $31.43 \pm 4.76$ and $11.67 \pm 3.41$ in the negative control group and the pshSTAT3 plus IR group, respectively (Fig. 4E).

Apoptosis assay. The results of FCM revealed statistical differences among the different treatment groups in the apoptotic rate $(\mathrm{F}=122.40, \mathrm{P}<0.05)$. As shown in Fig. 5, apoptotic rates were $37.04 \pm 1.59,24.87 \pm 3.26,29.49 \pm 2.69$ and $6.89 \pm 0.67 \%$ in the pshSTAT3 plus IR, IR, pshSTAT3 and negative control groups, respectively, with the highest rate in the pshSTAT3 plus IR group and the lowest rate in the negative control group.
Correlation analysis. Statistically significant correlations between different factors are summarized in Table I and Fig. 6. As shown, significant correlations were noted between p-STAT3 protein expression and expression of the other three downstream regulating proteins, including p-STAT3 vs. p53 $(\mathrm{r}=0.738, \mathrm{P}=0.000), \mathrm{p}-\mathrm{STAT} 3$ vs. VEGF $(\mathrm{r}=0.735, \mathrm{P}=0.000)$ and $\mathrm{p}-\mathrm{STAT} 3$ vs. $\mathrm{Bcl}-2(\mathrm{r}=0.727, \mathrm{P}=0.000)$, and also between the protein expression of p53 and VEGF and MVD counts, including p53 vs. MVD ( $\mathrm{r}=0.784, \mathrm{P}=0.000)$ and VEGF vs. $\mathrm{MVD}(\mathrm{r}=0.641, \mathrm{P}=0.000)$. An inverse correlation was observed between the protein expression of $\mathrm{Bcl}-2$ and the cell apoptosis rate $(\mathrm{r}=-0.883, \mathrm{P}=0.000)$.

\section{Discussion}

STATs are a family of proteins that act as signal messengers and transcription factors and participate in normal cellular responses to cytokines and growth factors. STAT3 is an important member of the STAT family, and is often associated with a wide variety of human malignancies, including head and neck cancer (21). STAT3 may mediate resistance to ionizing radiation or chemotherapeutic agents in certain malignant tumors, as evidenced by previous studies (22-24). For example, one study indicated that when the STAT3 gene is knocked out, B-1 cells become more susceptible to irradiation (25). It has also been reported that STAT3 inhibition with a STAT3 antisense oligonucleotide enhances radiation-induced apoptosis in prostate cancer cells (26). Furthermore, our previous study demonstrated that blocking STAT3 expression by siRNA potentiates radiation-induced cell death in Hep-2 human laryngeal carcinoma cells (17). However, it is unclear whether the inhibition of STAT3 expression by means of RNAi promotes radiosensitivity in human laryngeal carcinoma in vivo.

Essentially, RNAi specifically degrades target mRNA without affecting the stability of non-homologous mRNA. With the properties of high stability and a reliable inhibitory efficacy on the targeted mRNA, it is easier for cells to uptake siRNA than antisense oligonucleotides (27). In the present study, we successfully transfected a plasmid carrying STAT3 shRNA into xenograft human laryngeal squamous carcinoma cells using liposome as a delivery carrier. The effects of STAT3 shRNA following a planned experimental scheme on radiosensitization were investigated in the xenograft tumors. Upon termination of the experiment, tumor volume and weight in the pshSTAT3 plus radiation group were found to be dramatically reduced compared to the other groups. This indicates that a specific tumor inhibitory effect is achieved by pshSTAT3 plus radiation, superior to that achieved by radiotherapy or RNAi alone.

To explore the mechanism of radiosensitization by STAT3 shRNA in laryngeal carcinoma xenografts, the expression of STAT3 and its downstream regulating proteins as well as the associated cell apoptosis rates were evaluated. The results of protein expression from immunohistochemistry achieved by computerized image analysis demonstrated that the level of p-STAT3 decreased notably in animals treated by pshSTAT3 plus radiation, with simultaneous down-regulation of Bcl-2, p53 and VEGF protein expression. Tumor angiogenesis was also significantly suppressed, as evidenced by the MVD count. 

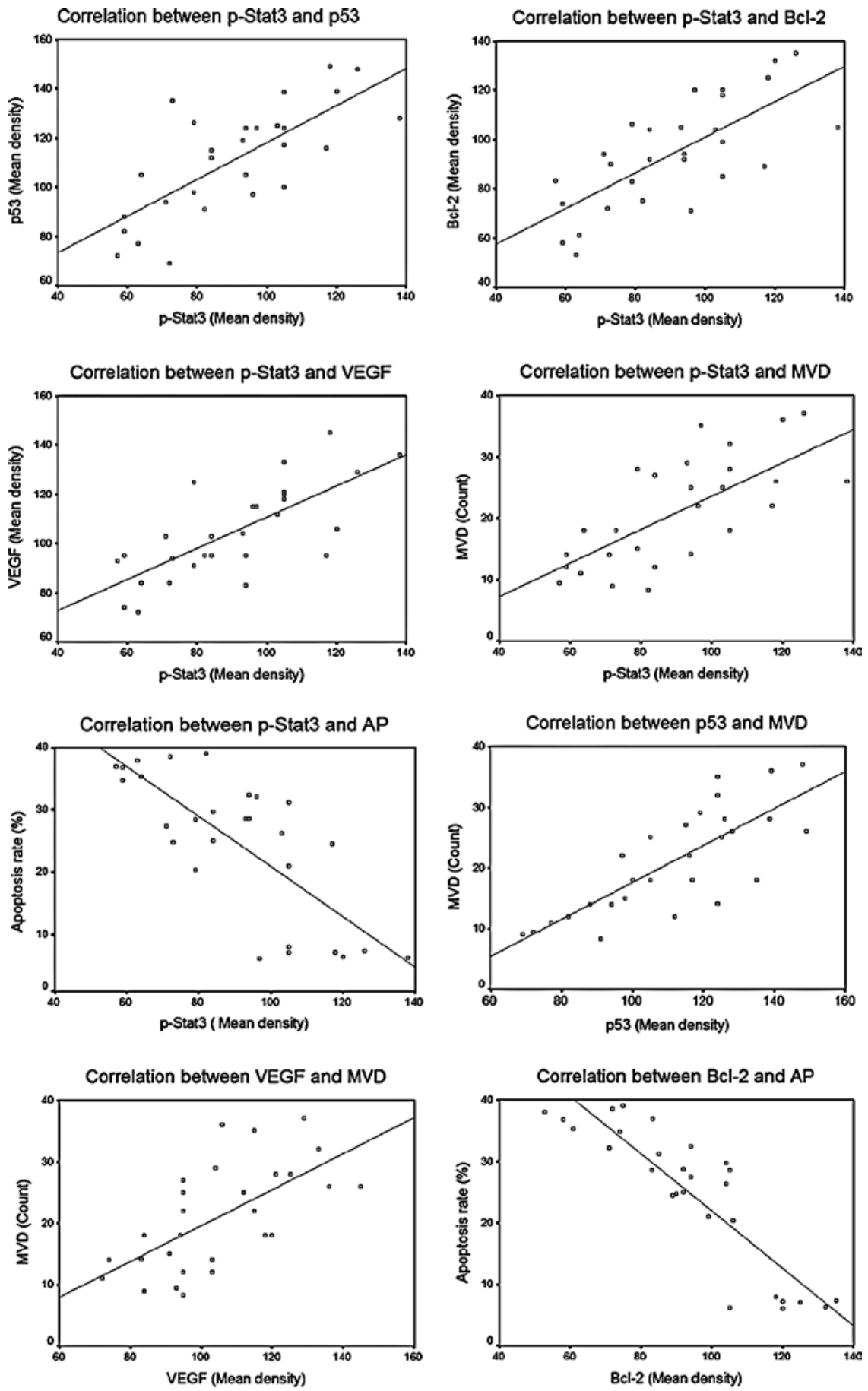

Figure 6. Scatter plots of analysis of correlation between factors.

Furthermore, the results of FCM demonstrated that the apoptosis rate of tumor cells in the pshSTAT3 plus radiation group was the highest among the different groups. These changes may be attributed to the regulation of downstream signaling proteins and tumor cell apoptosis by p-STAT3, an activated form of STAT3.

It is known that numerous important signaling proteins are present downstream of the STAT3 pathway. These include cell cycle regulators (c-Myc and CyclinD1/D2), anti-apoptotic proteins (Mcl-1 and Bcl-2) and tumor suppressor factors (p53 and VEGF). These are regulated to promote cell proliferation, inhibit cell apoptosis and potentiate tumor angiogenesis, and participate in the oncogenesis and development of tumors $(4,28,29)$. In the present study, the protein expression of p-STAT3, Bcl-2, p53 and VEGF was investigated. Correlation analysis of protein expression in the different groups demonstrated that the down-regulation of Bcl-2, p53 and VEGF by p-Stat3 is responsible for an increase in apoptosis and suppression of angiogenesis, resulting in radiosensitization effects in laryngeal carcinoma xenografts. In conclusion, STAT3 shRNA potentiate the radiosensitivity of laryngeal carcinoma xenografts in vivo by regulating downstream signaling proteins in the STAT3 pathway, which exerts potent effects on the induction of apoptosis and inhibition of angiogenesis. 


\section{References}

1. Rhee JG, Li D, O'Malley BW Jr and Suntharalingam M: Combination radiation and adenovirus-mediated P16(INK4A) gene therapy in a murine model for head and neck cancer. ORL J Otorhinolaryngol Relat Spec 65: 144-154, 2003.

2. Rhee JG, Li D, Suntharalingam M, Guo C, O'Malley BW Jr and Carney JP: Radiosensitization of head/neck squamous cell carcinoma by adenovirus-mediated expression of the Nbs1 protein. Int J Radiat Oncol Biol Phys 67: 273-278, 2007.

3. Takeda K, Noguchi K, Shi W, et al: Targeted disruption of the mouse Stat 3 gene leads to early embryonic lethality. Proc Natl Acad Sci USA 94: 3801-3804, 1997.

4. Fukada T, Ohtani T, Yoshida Y, et al: STAT3 orchestrates contradictory signals in cytokine-induced G1 to S cell-cycle transition. EMBO J 17: 6670-6677, 1998.

5. Catlett-Falcone R, Landowski TH, Oshiro MM, et al: Constitutive activation of Stat 3 signaling confers resistance to apoptosis in human U266 myeloma cells. Immunity 10: 105-115, 1999.

6. Bromberg JF: Activation of STAT proteins and growth control. Bioessays 23: 161-169, 2001.

7. Niu G, Wright KL, Ma Y, et al: Role of Stat3 in regulating p53 expression and function. Mol Cell Biol 25: 7432-7440, 2005.

8. Odajima J, Matsumura I, Sonoyama J, et al: Full oncogenic activities of $\mathrm{v}-\mathrm{Src}$ are mediated by multiple signaling pathways Ras as an essential mediator for cell survival. J Biol Chem 275 24096-24105, 2000

9. Ning ZQ, Li J, McGuinness M and Arceci RJ: STAT3 activation is required for $\mathrm{Asp}(816)$ mutant c-Kit induced tumorigenicity. Oncogene 20: 4528-4536, 2001.

10. Bowman T, Broome MA, Sinibaldi D, et al: Stat3-mediated Myc expression is required for Src transformation and PDGF-induced mitogenesis. Proc Natl Acad Sci USA 98: 7319-7324, 2001.

11. Sinibaldi D, Wharton W, Turkson J, Bowman T, Pledger WJ and Jove R: Induction of p21WAF1/CIP1 and cyclin D1 expression by the Src oncoprotein in mouse fibroblasts: role of activated STAT3 signaling. Oncogene 19: 5419-5427, 2000.

12. Karni R, Jove R and Levitzki A: Inhibition of pp60c-Src reduces $\mathrm{Bcl}-\mathrm{XL}$ expression and reverses the transformed phenotype of cells overexpressing EGF and HER-2 receptors. Oncogene 18: 4654-4662, 1999.

13. Aoki Y, Feldman GM and Tosato G: Inhibition of STAT3 signaling induces apoptosis and decreases survivin expression in primary effusion lymphoma. Blood 101: 1535-1542, 2003.

14. Gritsko T, Williams A, Turkson J, et al: Persistent activation of stat3 signaling induces survivin gene expression and confers resistance to apoptosis in human breast cancer cells. Clin Cancer Res 12: 11-19, 2006

15. Epling-Burnette PK, Liu JH, Catlett-Falcone R, et al: Inhibition of STAT3 signaling leads to apoptosis of leukemic large granular lymphocytes and decreased Mcl-1 expression. J Clin Invest 107: 351-362, 2001.
16. Wei D, Le X, Zheng L, et al: Stat3 activation regulates the expression of vascular endothelial growth factor and human pancreatic cancer angiogenesis and metastasis. Oncogene 22: 319-329, 2003.

17. Li X, Wang H, Lu X and Di B: STAT3 blockade with shRNA enhances radiosensitivity in Hep-2 human laryngeal squamous carcinoma cells. Oncol Rep 23: 345-353, 2010.

18. Bissery MC, Guenard D, Gueritte-Voegelein F and Lavelle F: Experimental antitumor activity of taxotere (RP 56976, NSC 628503), a taxol analogue. Cancer Res 51: 4845-4852, 1991.

19. Crisby M, Nordin-Fredriksson G, Shah PK, Yano J, Zhu J and Nilsson J: Pravastatin treatment increases collagen content and decreases lipid content, inflammation, metalloproteinases, and cell death in human carotid plaques: implications for plaque stabilization. Circulation 103: 926-933, 2001.

20. Weidner N, Semple JP, Welch WR and Folkman J: Tumor angiogenesis and metastasis - correlation in invasive breast carcinoma. N Engl J Med 324: 1-8, 1991.

21. Turkson $\mathbf{J}$ and Jove R: STAT proteins: novel molecular targets for cancer drug discovery. Oncogene 19: 6613-6626, 2000.

22. Bharti AC, Shishodia S, Reuben JM, et al: Nuclear factor-kappaB and STAT3 are constitutively active in CD138+ cells derived from multiple myeloma patients, and suppression of these transcription factors leads to apoptosis. Blood 103: 3175-3184, 2004.

23. Greten FR, Weber CK, Greten TF, et al: Stat 3 and NF-kappaB activation prevents apoptosis in pancreatic carcinogenesis. Gastroenterology 123: 2052-2063, 2002.

24. Real PJ, Sierra A, De Juan A, Segovia JC, Lopez-Vega JM and Fernandez-Luna JL: Resistance to chemotherapy via Stat3dependent overexpression of $\mathrm{Bcl}-2$ in metastatic breast cancer cells. Oncogene 21: 7611-7618, 2002.

25. Otero DC, Poli V, David M and Rickert RC: Cutting edge: inherent and acquired resistance to radiation-induced apoptosis in B cells: a pivotal role for STAT3. J Immunol 177: 6593-6597, 2006.

26. Calvin DP, Nam S, Buettner R, Sekharam M, Torres-Roca J and Jove R: Inhibition of STAT3 activity with STAT3 antisense oligonucleotide (STAT3-ASO) enhances radiation induced apoptosis in DU145 prostate cancer cells. Int J Radiat Oncol Biol Phys 57: S297, 2003.

27. Zhang YC, Taylor MM, Samson WK and Phillips MI: Antisense inhibition: oligonucleotides, ribozymes, and siRNAs. Methods Mol Med 106: 11-34, 2005.

28. Amin HM, McDonnell TJ, Ma Y, et al: Selective inhibition of STAT3 induces apoptosis and G(1) cell cycle arrest in ALK-positive anaplastic large cell lymphoma. Oncogene 23: 5426-5434, 2004.

29. Niu G, Wright KL, Huang M, et al: Constitutive Stat3 activity up-regulates VEGF expression and tumor angiogenesis. Oncogene 21: 2000-2008, 2002. 